\title{
The relationship between irrational gambling beliefs and gambling behavior: application of autoregressive cross-lagged modeling.
}

\author{
Young Ran Yeun ${ }^{1}$, Dong Il Chun², Hee Yeong Woo ${ }^{3^{*}}$ \\ ${ }^{1}$ Department of Nursing, Kangwon National University, 346 Hwangjogil, Dogyeeup, Samcheok, Gangwondo, Republic \\ of Korea \\ ${ }^{2}$ Department of Social Welfare, Kangwon National University, 346 Hwangjogil, Dogyeeup, Samcheok, Gangwondo, \\ Republic of Korea
}

${ }^{3}$ Department of Nursing, Sahmyook Health University, 82 Manguro, Dongdaemun-gu Seoul, Republic of Korea

\begin{abstract}
The purpose of this study was to identify the longitudinal causality between gambling beliefs and gambling behavior. An online survey was conducted 3 times across 10 months (January, May, and October) among adult gamblers $(\mathrm{N}=\mathbf{3 4 0})$ who had more than one year of regular gambling behavior, at least once a month ( $\mathrm{N}=340,64.7 \%$ males). The mean age of the subjects was $40.34 \mathrm{y}(\mathrm{SD}=\mathbf{0 . 4 3})$. The causality between irrational gambling beliefs and gambling behavior was analysed using autoregressive cross-lagged modeling. Analysis showed that gambling beliefs affected gambling behavior after 5 months $(B=0.152, p<0.001)$, and gambling behavior also affected gambling beliefs after 5 months $(B=0.090$, $\mathbf{p}<0.01)$. These results explain that there is a mutual causality between irrational gambling beliefs and gambling behavior. Thus, the gambling disorder treatment programs should take into account not only cognitive behavioral theory but the cognitive dissonance perspective.
\end{abstract}

Keywords: Gambling disorder, Gambling beliefs, Gambling behavior, Autoregressive cross-lagged modeling. Accepted on December 26, 2018

\section{Introduction}

Lately, gambling disorder (GD) has been one of the most serious behavioral addictions in South Korea. Irrational gambling beliefs (IGBs) are inaccurate expectations or perceptions concerning gambling processes or outcomes, and have been found to directly or indirectly affect gambling addiction in many previous studies [1,2]. The results of these previous studies support the importance of cognitive behavioral therapy (CBT) for GD. However, there have been somewhat pessimistic findings concerning the effectiveness of GD treatment programs based on CBT $[3,4]$. As opposed to cognitive behavioral theory, cognitive dissonance theory argues that problematic behavior may cause irrational beliefs. Cognitive dissonance is a state of tension that occurs when one behaves in a psychologically inconsistent way $[5,6]$. When the two aforementioned theories are compared in order to establish a future direction for GD treatment programs, it is important to first test the causality between IGBs and gambling behavior. Therefore, this study aimed to identify the direction and degree of causality between IGBs and gambling behavior and to provide basic data to support the provision of an intervention for GD when its symptoms are observed.

\section{Materials and Methods}

The research data provided by the National Research Foundation of Korea (NRF) were downloaded from the foundation's Basic Research Resource Center website [7]. The data were collected through an online survey (January, May, and October). The survey participants were 340 gamblers who had gambled at least once a month for more than a year. The mean age of the participants was 40.34 y $(\mathrm{SD}=0.43)$, and $64.7 \%$ of them were males. The education level of $253(74.4 \%)$ of the participants was higher than college and $238(70.0 \%)$ of the participants were regular workers. The research was reviewed and approved by the Institutional Review Board of Kangwon National University. The reliability of an Irrational Gambling Beliefs Scale [8], as measured in the first round was 0.93 , and 0.95 in the second and third rounds. The reliability of the gambling behavior scale [9], as measured in both the first and second rounds was 0.89 , and 0.90 in the third round. The change trend between IGBs and gambling behavior was analysed using descriptive statistics, while the causality between IGBs and gambling behavior was analysed using autoregressive cross-lagged (ARCL) modeling. ARCL modeling on panel data can control individual variables, allowing for the testing of the direction of causality between two or more variables. For analysis, SPSS 20.0 was used to 
generate descriptive statistics, and AMOS was used for ARCL modeling.

\section{Results}

During the study period, gambling behavior and IGBs decreased over time. Five models were set (Models 1-8) based on the assumptions of measurement invariance, path invariance for the autoregressive coefficients, and path invariance for the cross-regressive coefficients. It was judged that it is appropriate to use Model 8 for ARCL modeling for IGBs and gambling behavior (Table 1). In terms of the cross-regressive coefficients representing the significance of the cross-lagged path, all the paths between the $1^{\text {st }}$ IGBs and the $2^{\text {nd }}$ gambling behavior, between the $2^{\text {nd }}$ IGBs and the $3^{\text {rd }}$ gambling behavior, between the $1^{\text {st }}$ gambling behavior and the $2^{\text {nd }}$ IGBs, and between the $2^{\text {nd }}$ gambling behavior and the $3^{\text {rd }}$ IGBs were found to be significant. This suggests that gambling behavior affects IGBs, and that IGBs also affect gambling behavior (Table 2).

Table 1. Comparison of model's goodness of fit.

\begin{tabular}{|c|c|c|c|c|c|}
\hline Model & $x^{2}$ & df & TLI & CFI & RMSEA \\
\hline Model 1. Basic model & 5849.048 & 934 & 0.711 & 0.727 & 0.125 \\
\hline Model 2. Measurement invariance (IGBs) & 5866.28 & 944 & 0.714 & 0.727 & 0.124 \\
\hline Model 3. Measurement invariance (GB) & 5990.07 & 960 & 0.712 & 0.721 & 0.124 \\
\hline Model 4. Path invariance (AC) (IGBs $\rightarrow$ IGBs) & 5990.514 & 961 & 0.713 & 0.721 & 0.124 \\
\hline Model 5. Path invariance $(\mathrm{AC})(\mathrm{GB} \rightarrow \mathrm{GB})$ & 5999.826 & 962 & 0.713 & 0.721 & 0.124 \\
\hline Model 6. Path invariance (CC) (IGBs $\rightarrow$ GB) & 6003.217 & 963 & 0.713 & 0.721 & 0.124 \\
\hline Model 7. Path invariance (CC) (GB $\rightarrow$ IGBs) & 6004.189 & 964 & 0.713 & 0.721 & 0.124 \\
\hline Model 8. Error covariance invariance & 6004.2 & 965 & 0.713 & 0.721 & 0.124 \\
\hline
\end{tabular}

IGBs: Irrational Gambling Beliefs; GB: Gambling Behavior; AC: Autoregressive Coefficient; CC: Cross-Regressive Coefficient.

Table 2. Short-term longitudinal relationship between gambling beliefs and gambling behavior.

\begin{tabular}{|c|c|c|c|c|}
\hline Path & $\begin{array}{l}\text { Non- } \\
\text { standardized }\end{array}$ & SE & Standardized & CR \\
\hline \multicolumn{5}{|l|}{ Autoregressive path } \\
\hline $\operatorname{IGBs}\left(1^{\mathrm{st}}\right) \rightarrow \operatorname{IGBs}(2 \mathrm{nd})$ & 0.754 & 0.032 & 0.752 & $23.558^{* *}$ \\
\hline IGBs $\left(2^{\text {nd }}\right) \rightarrow$ IGBs $\left(3^{\text {rd }}\right)$ & 0.754 & 0.032 & 0.752 & $23.558^{* *}$ \\
\hline $\mathrm{GB}\left(1^{\mathrm{st}}\right) \rightarrow \mathrm{GB}(2 \mathrm{nd})$ & 0.684 & 0.03 & 0.716 & $22.954^{* *}$ \\
\hline $\mathrm{GB}\left(2^{\text {nd }}\right) \rightarrow \mathrm{GB}\left(3^{\text {rd }}\right)$ & 0.684 & 0.03 & 0.715 & $22.954^{* *}$ \\
\hline \multicolumn{5}{|l|}{ Cross-lagged path } \\
\hline $\operatorname{IGBs}\left(1^{\text {st }}\right) \rightarrow \mathrm{GB}\left(2^{\text {nd }}\right)$ & 0.152 & 0.032 & 0.147 & $4.765^{\star \star \star}$ \\
\hline IGBs $\left(2^{\text {nd }}\right) \rightarrow$ GB $\left(3^{\text {rd }}\right)$ & 0.152 & 0.032 & 0.154 & $4.765^{* * *}$ \\
\hline $\mathrm{GB}\left(1^{\mathrm{st}}\right) \rightarrow \operatorname{IGBs}\left(2^{\text {nd }}\right)$ & 0.09 & 0.03 & 0.097 & $2.968^{\star *}$ \\
\hline GB $\left(2^{\text {nd }}\right) \rightarrow$ IGBs $\left(3^{\text {rd }}\right)$ & 0.09 & 0.03 & 0.092 & $2.968^{* *}$ \\
\hline
\end{tabular}

\section{Discussion}

The purpose of this study was to test the causal direction between gambling-related irrational beliefs and gambling behavior. First, the results of this study imply that the relationship between IGBs and gambling behavior can be better explained by the interaction between the two rather than by cognitive behavioral theory or cognitive dissonance theory. While the main theory of gambling disorder, stating that IGBs lead to gambling behavior is reasonable [10], GD can also be explained by cognitive dissonance theory [11], which states that people change their beliefs after engaging in gambling behavior to rationalize their behavior. Therefore, GD treatment programs should take into account not only cognitive behavioral theory but the cognitive dissonance perspective. This study is different from other previous studies in purpose, analysis method, and model. For example, Kwon [12] used the Latent Growth Model to analyse the change trajectories of gambling beliefs and gambling behaviors, whereas this study used an autoregressive cross delay model to test causality. In addition, Kwon [12] assumed that the gambling belief had a one-way influence on gambling behavior. On the other hand, this study set up a model with the possibility that gambling behavior may influence gambling belief by cognitive dissonance phenomenon.

\section{References}

1. Yang JN, Choi EJ, Lee MH, So Y. Depression, impulsive behaviour and family health factors affects irrational belief of gambling and gambling behaviour of young people. Korean J Youth Studies 2011; 18: 357-383. 
The relationship between irrational gambling beliefs and gambling behavior: application of autoregressive crosslagged modeling

2. Kim SR, Kwon YS, Hyun MH. The effects of belief in good luck and counterfactual thinking on gambling behavior. J Behav Addict 2015; 4: 236-243.

3. Challet-Bouju G, Bruneau M, IGNACE Group, VictorriVigneau C, Grall-Bronnec M. Cognitive remediation interventions for gambling disorder: a systematic review. Front Psychol 2017; 8: 1961.

4. Cowlishaw S, Merkouris S, Dowling N, Anderson C, Jackson A, Thomas S. Psychological therapies for pathological and problem gambling. Cochrane Database Syst Rev 2012; 11: 008937.

5. Festinger L. A theory of cognitive dissonance. Stanford Unversity Press 1957.

6. Chung SH, Cheng KC. How does cognitive dissonance influence the sunk cost effect? Psychol Res Behav Manag 2018; 11: 37-45.

7. Basic Research Resource Center. NRF-2011-332-B00744. https: //www.krm.or.kr.

8. Kwon SJ. Gambling related belief and problem gambling revisited: a test of position of gambling related belief using Latent growth curve modeling. Korean J Youth Studies 2014; 21: 359-376.

9. National Gambling Control Commission. 2009 survey on the use of gambling industry. http: //www.ngcc.go.kr/data/ pdsView.do.

10. Merkouris SS, Thomas SA, Browning CJ, Dowling NA. Predictors of outcomes of psychological treatments for disordered gambling: a systematic review. Clin Psychol Rev 2016; 48: 7-31.

11. Auer M, Griffiths MD. An empirical investigation of theoretical loss and gambling intensity. J Gambl Stud 2014; 30: 879-887.

12. Kwon SJ. Gambling related belief and problem gambling revisited: a test of position of gambling related belief using Latent growth curve modeling. Korean J Youth Studies 2014; 21: 359-376.

13. Hinojosa AS, Gardner WL, Walker HJ, Cogliser C, Gullifor D. A review of cognitive dissonance theory in management research: opportunities for further development. J Manag 2017; 43: 170-199.

14. Zhang L, Xia Y, Liu B, Han L. Why dont I help you? The relationship between role stressors and helping behavior from a cognitive dissonance perspective. Front Psychol 2018; 8: 2220.

\section{*Correspondence to}

Hee Yeong Woo

Department of Nursing

Sahmyook Health University

Republic of Korea 